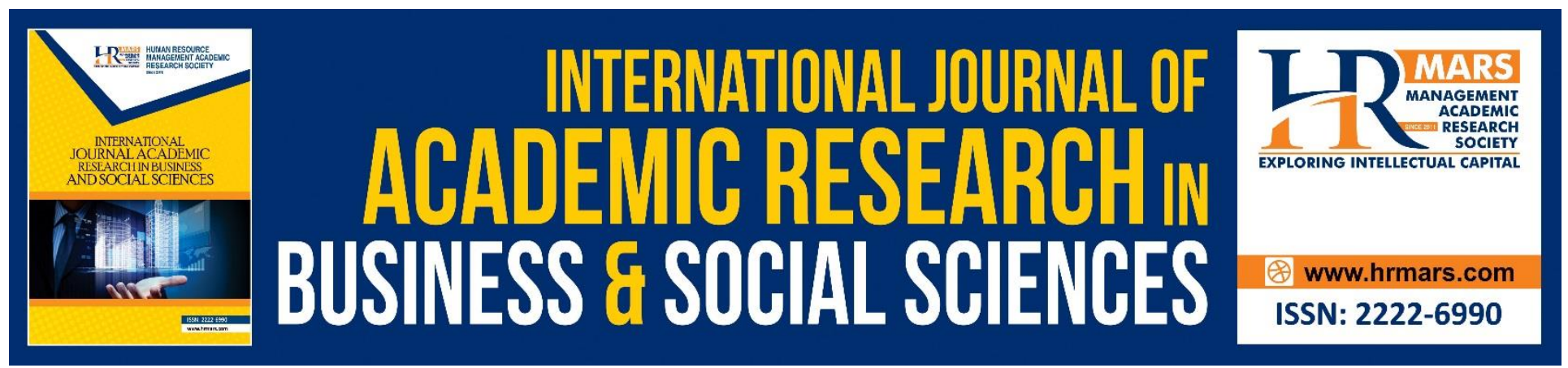

\title{
Digitization of Records and Archives: Issues and Concerns
}

\author{
Nur Atiqah Mohd Azim, Saiful Farik Mat Yatin, Rayson Clinsmund Anak \\ Jensonray, Syahirah Ayub@Mansor
}

To Link this Article: http://dx.doi.org/10.6007/IJARBSS/v8-i9/4582

DOI: $\quad 10.6007 /$ IJARBSS/v8-i9/4582

Received: 12 July 2018, Revised: 23 August 2018, Accepted: 29 August 2018

Published Online: 29 September 2018

In-Text Citation: (Azim, Yatin, Jensonray, \& Ayub@Mansor, 2018)

To Cite this Article: Azim, N. A. M., Yatin, S. F. M., Jensonray, R. C. A., \& Ayub@Mansor, S. (2018). Digitization of Records and Archives: Issues and Concerns. International Journal of Academic Research in Business and Social Sciences, 8(9), 170-178.

Copyright: (C) 2018 The Author(s)

Published by Human Resource Management Academic Research Society (www.hrmars.com)

This article is published under the Creative Commons Attribution (CC BY 4.0) license. Anyone may reproduce, distribute, translate and create derivative works of this article (for both commercial and non-commercial purposes), subject to full attribution to the original publication and authors. The full terms of this license may be seen at: http://creativecommons.org/licences/by/4.0/legalcode

Vol. 8, No. 9, September 2018, Pg. 170 - 178

Full Terms \& Conditions of access and use can be found at http://hrmars.com/index.php/pages/detail/publication-ethics 


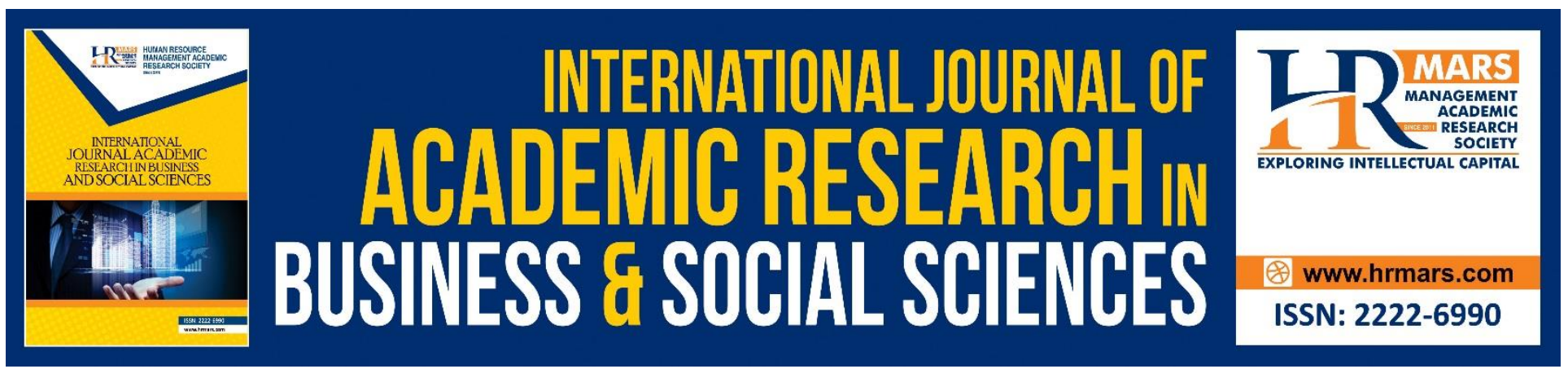

\title{
Digitization of Records and Archives: Issues and Concerns
}

\author{
Nur Atiqah Mohd Azim, Saiful Farik Mat Yatin, Rayson Clinsmund \\ Anak Jensonray, Syahirah Ayub@Mansor \\ Faculty of Information Management, Puncak Perdana Campus, Universiti Teknologi MARA (UiTM), \\ UiTM Selangor, Malaysia
}

\begin{abstract}
Digitization is the process of converting information into a digital format. Records is an information that are create, receive and maintain by an organization as an evidence while archive is a document that contain historical background for the country and organization. Archives contain primary source documents that have accumulated over the course of an individual or organization's lifetime, and are kept to show the function of that person or organization. Nowadays, digitization is a new method for records and archives management to keep their record or document for further lifetime existence. Digitization can dramatically increase accessibility, creating more ways to present your records to new and wider audiences.
\end{abstract}

Keywords: Archives, Records, Digitization, Organization, Technology

\section{Introduction}

Acknowledges by International Records Management Trust, An Introduction to Core Principles for Staff of the World Bank and Its Partners, released on July 2000 in page 15, records is a document regardless of form or medium created, received, maintained and used by an organization (public or private) or an individual in pursuance of legal obligations or in the transaction of business, of which it forms a part or provides evidence. Meanwhile, affirm by James B. Rhoads in his article, archives are inactive records, of enduring value selected for permanent preservation. Archives will normally be preserved in an archival repository.

\section{Important of records and archives}

United Nation Record and Archives Management Section (2010) state that records are the vital resources that an organization needs to conduct their operations efficiently and effectively. Without records, no public and private agencies could operate successfully. In other words, records are needed as a proof in any agencies activities. Records help organization's to:
a) Provide a corporate memory
b) Formulate policy
c) Make appropriate decisions. 
INTERNATIONAL JOURNAL OF ACADEMIC RESEARCH IN BUSINESS AND SOCIAL SCIENCES

Vol. 8, No. 9, Sept. 2018, E-ISSN: 2222-6990 @ 2018 HRMARS

d) Achieve greater efficiency, productivity and consistency

e) Meet statutory and regulatory requirements

f) Protect the organization's interests and those of its staff and clients.

g) Document all the organization activities and achievements.

\section{Digitization of Records and Archives}

Confirm by Malaysian Standard, in the policy of Information and documentation in Implementation guidelines for digitization of records, pages 4, digitization is a process of converting hard-copy or nondigital records into digital format. Supported by National Archives and Records Administration in the article of Strategy for Digitizing Archival Materials for Public Access 2015-2024, pages 3, "digitizing" is a process of preserving the records for further use in virtual form.

\section{Important of Digitization}

Confirmed by Malaysian Standard, in the policy of Information and documentation in Implementation guidelines for digitization of records, pages 4, Digitization offers the following potential benefits to organizations:

a) More than one person can use the records.

b) Can be access at any location.

c) Better integration with business information systems.

d) Capacity to transmit images within a structured workflow, thus assisting work processing;

e) Easy access when a big material such as map can be access by virtual.

f) Can be back-up during disaster.

g) Protected and secure.

h) Save space.

i) Increase productivity of organization.

\section{Risk of Digitization}

There are a number of risks associated with implementing a digitization process affirmed by Malaysian Standard, in the policy of Information and documentation in Implementation guidelines for digitization of records, pages 5:

a) Short-term cost savings in space may be negated when balanced with longer-term costs in maintaining the accessibility of digital images over time;

b) The organization need to use an expensive technology to operate the material.

c) Legislative, regulatory or other requirements to maintain authentic and reliable representations of non-digital source records may limit the capacity to deploy commonly offered digitization features (such as image manipulation, etc.);

d) It may not be appropriate to destroy the non-digital source records after the digitization process, especially where there are good reasons to retain the records in their non-digital form, e.g. records with importance for national or personal identity or other societal or cultural significance;

e) It may not be permissible to destroy the non-digital source records after the digitization process for legislative reasons (by law, some specific classes of records have to be retained in their original format and in some instances non-digitized records may even need to be retained along with their digitized counterparts for a period of time). 


\section{Policy of Digitization}

Guidelines or policy are very important in any process for digitization works. Many libraries and archives always to plan digitization projects but lack experience and there is a need for a practical guide as a working tool for planning digitization projects. Furthermore, this need is particularly felt in developing countries. In addition, from this guideline, there are six key components of a digital imaging project which is Selection Policy, Conversion, Quality Control Programme, Collection Management, Presentation and Maintaining Long Term Access.

So, there are many policies have been created by national an international organization or can be created with a legal and ethics in management of public archive, library and resource center. The organization plays an important role in manage the process of digitization. They have to make sure all the process followed the policy. By referring Guidelines for Digitization Projects for collections and holdings in the public domain, particularly those held by libraries and archives, International Federation of Library Associations and Institutions (IFLA) said, there are eight (8) criteria must be follow for digitization process in archives and libraries which is:

\section{Selection}

Selection is important to select the requirements of source material. There are issues that involved in the selection of materials for digitization that will be examined and it look from two (2) ways which are principal reasons for digitisation and criteria for selection (IFLA, 2002).

\section{Technical Requirements and Implementation}

For technical requirements and implementation are divided by three important elements. There are Conversion, Quality Control and Collection Management. From this guideline, IFLA (2002) discuss that a digital image is an 'electronic photograph' and mapped as a grid dots or element of picture. Usually

it is used for scanning, compression, storage and printing. In these criteria the question that rises are about the attributes of the sources documents to be digitised and the image quality.

From conversion, the attributes of the document are very important. For the resolution, bit depth and the compression must be choose properly for the quality of the images. The equipment used also has an important effect on the quality of the materials such as image. It must be considered with a good judgement and care. There must be staff at there to look on the equipment.

Then, every stage of digitisation work must be adapted with all the component for quality control because that is very important to the project. They should know an important scope and methods in digitization process. Scanning quality control must be set. The issues in thus performance are spatial resolution, Tonal reproduction, Colour reproduction, Noise, and Artefacts. To get a better result in digitization, they must monitor the quality and always viewing the conditions.

Collection management is important on how the collection is managed. Staff must follow and study the background of all the guideline. This guideline shows how to decided and stored an image. The images must be named and described and also put it on where their located. The used of metadata of images also important for external and internal process.

\section{Legal Aspects}

In digitization process, they need to be aware in focus to the authenticity of digital images created and produced if they are to serve as substitutes for the original source materials. IFLA, (2002) suggest 
INTERNATIONAL JOURNAL OF ACADEMIC RESEARCH IN BUSINESS AND SOCIAL SCIENCES

Vol. 8, No. 9, Sept. 2018, E-ISSN: 2222-6990 @ 2018 HRMARS

that these criteria are divided by four (4) which is copyright, authenticity, intellectual property management and also legal deposit.

\section{Budgeting}

By referring IFLA guidelines, they explained that to build a digital collection is very costly and require exclusive access for large amount of data. The budget must be used properly. So, in these criteria, cost recovery can offer small compensation to the high capital expenditure associated with digitization. Staff development, facilities management, and operational expenses are included for the areas of expenditure. For an example, staff that work on develop and produce the materials in digital library also involve in the budget. It is a selection and preparation of source material for digitization, digital conversion, metadata capture and data management. Managing storage must direct the management in handle their storage with a proper budget and the delivery systems must be always function in used and in a good maintenance.

\section{Human Resource Planning}

All the management in libraries and archives are play an important role in the organization. In IFLA guidelines, there must be a staff of library and archive that have been inform to the student of a new skills and they will respond to the digital environment and it is actually service providers in staff education and qualification. There are three main areas that must be considered are change management, capacity building and social contract. For the management, it may be different and it is to examine the problems of interaction within the management culture, a lack of managerial support and fear in term of technological innovations. The capacity building effectively achieved by forming partnerships, who in their dedication to making it work, ensure the improvement of skills and increase the possibility for a successful outcome of the projects. After that, the social contract is a component part that provided all new job opportunities to people. This can make them have valueadded in their attitude to become more professionals.

\section{Development and Maintenance of Web Interfaces}

Nowadays, an IT and Computer are mostly used by all communities. IFLA suggest, the unique properties of the digital medium give visual form to cultural heritage information. So, there are four organizational issues to create and maintain online information resources which are Develop the content in digital term, build a team to develop Web, Produce and manage Web and also Provide services in introduce Web-based. After they completed to develop digital content, a Web team should be builds for worker to access sites and to see what characteristics and update work to make the pages more interesting for users. In producing and managing a Website, there must be a guideline, which are File and folder structure, File naming conventions, Page layout and design, Webready Graphics, Minimum requirements, and Site maintenance. And these guidelines also said that the ultimate challenge is when applying and use digital technologies to develop the services provide in Web-based. It is required in content of image indexing and the management access to digitized collections. IT value in this guideline can give staff to perform a better work.

\section{Preservation of Digital Content}

Digital content must be preserved to further used. The storage after this materials preserve is important. This is because to avoid all the information on the materials loss. This is also can be a current or future reference to avoid risk. In this criterion, there are six (6) content that related which 
INTERNATIONAL JOURNAL OF ACADEMIC RESEARCH IN BUSINESS AND SOCIAL SCIENCES

Vol. 8, No. 9, Sept. 2018, E-ISSN: 2222-6990 @ 2018 HRMARS

are preservation challenges, policy development at the point capture, international standards, nonproprietary models, persistent archive management and trusted digital repositories.

\section{Project Management}

In digitization project, all the project management must have a plan and follow the steps required to achieve the vision and mission. The responsibilities of the project manager can bring a better proposal for the current project. This guideline shows how to create and manage the project of digitization. In proposal writing it might have a draft format which are Introduction, Vision and mission, Needs assessment, Activities, Performance Indicators, Responsible people and also Time frame of the project. The budget in this project also are important. In managing the expenditure along the time of the project, Operational costs, includes materials, equipment, transport and service; Organizational costs, includes management, administration, organizational development and overhead; lastly, staffing costs, includes Full-time staff, Part-time staff, Contract staff and Consultants will assist. The project manager should ensure that digitisation cycle must be in the whole process. This chain in the production process must be follow. Workflow must be managed properly. It is reached in three (3) ways which is in the supervision of a quality control programmed, in the regular documentation of progress at established reporting intervals and in the establishment of a tracking system.

\section{Issues and Concern of Digitization}

Many of decision maker's archive and library managers, curatorial and technical staff members and also particular users that responsible in handling the digitization work always faced many issue and they must be concern on what they doing in digitization process. The issue can be a positive issue and also a negative issue. But, the management of assets for digital process presents new challenges to the archive and library community in terms of using and managing complex hardware and software, but mass digitization has not changed the fundamentals of services in archive and library. There are many issues and concern that they must face which are:

\section{Legal Aspects}

Pandey and Misra (2014), opines that in the academic library, the issues were much connected to intellectual property rights. It is a major problem for the user when act in accordance with all these especially issues like plagiarism (Warwick, et.al, 2008). Nowadays, people tend to be a professional but they do not have their skill on what they try to do. It will affect the abilities of libraries or information agencies to provide digital collections and services. For example, they must have evidence how they digitize the materials and from where they get the materials. The serious concerns must associate with the principles of sharing or providing access to fold or ethnographic materials.

\section{Untrained Staff and Human Error}

By referring to Routhier Perry (2014), she discusses that all staff and human still can perform in using the digital technology. When human error come, many library and archives staff members do not have the required training and skills in doing digitization process. So, using staff that have not formally educated in digital activities will come with risks. It also will lead to difficult decisions and also the organizations will spend more money to cover all it such as, expertise training, deterioration of materials, equipment and also facilities. At the end, the result also comes out with a bad result. In term of technophobia, it is lack the ability of the traditional staff that have phobia in using technology. They feel and think that they difficult to use the technology to complete their work. As 
INTERNATIONAL JOURNAL OF ACADEMIC RESEARCH IN BUSINESS AND SOCIAL SCIENCES

Vol. 8, No. 9, Sept. 2018, E-ISSN: 2222-6990 @ 2018 HRMARS

we can see, staff and students with suitable and good skills, capabilities and attitude are not ready to carry out the digitization project. Teaching them each time the job is very time consuming (Pandey and Misra, 2014).

\section{Changing Formats and Obsolescence of Technology}

There are many issues surrounding that focus to the technology. Nowadays, as we know, technology is quickly changing and it is a major challenge for the users. Not only difficult in digitize the hardware, software also difficult to access. Format and data nowadays have change every time. All the effort to reformat or re change any object into digital, the result will loss explained by Routhier Perry (2014). Then, in term of Technological Obsolescence, by referring to Pandey and Misra (2014), more and more days, to ensure the technology are no longer produced and used, the digital archives should be transcribed. It can lead to the loss of the means to access to information in digital form. It also caused by the working system and also their storage media.

\section{Funding}

Digital projects are very expensive. So, archive and library must have an enough budget. Digitization work in archive and library requires more funding to support the entire project that use in upgrading the automation of hardware and software and it also increase the cost to subscribe all the materials in term of electronic and databases. They must make a planning to get more funds from outside organization. Archivists that have been trained in digitization and preservation of electronic format creates a herculean problem. An expertly fund digitization project convinces new and raised services and sustainability of the project. They must know how to find the best fund in any organization (Pandey and Misra, 2014).

\section{Refreshing and standardization}

Another major issue is refreshing. Archive and library will transfer any materials to better physical storage media in order to upgrade the materials from old version. Loss of format will give some trouble to staff or user in access it. It may be lost as digital materials when it comes in modern ways environments. It explained by Pandey and Misra (2014). In addition, in term of standardized, some metadata or materials are not standardized. It also comes with same words and descriptions and it makes many of errors. When it becomes automated, it will difficult for staff to manage and arrange back to determine all the materials. This issue can waste the time to arrange it again (Routhier Perry, 2014).

\section{Constantly Changing Software and Hardware}

Pandey and Misra also explains that software and hardware can be changing any time and it provides major force on archival institutions because preservation of digital archival collections centers on the interim mechanism for storing the information that in digital format, transfer to new form and supplying long term access. Moreover, the technology has been upgraded. So, this is a challenge that must be faced for the staff. One of the major difficulties facing the longevity of digital collections is not only the storage media deterioration, but the problem of rapidly changing storage devices. Unlike analogue information which places emphasis on the preservation of physical artifacts, it is the informational contents of the digitized material that is preserved. It will therefore take a conscious effort of archivists to make sure that the digital information is preserved since 'continuously change software and hardware creates headache for staff working on digital longevity' (Besser, 1999). 


\section{Emulation}

The objective of emulation is for older data-sets to run on contemporary computers. Emulation is focuses on the applications in any software rather than on the files containing the data and it is similar to migration. The data can change easily, and it is very difficult to the staff to find or open it again. It tried to develop advanced tools that will create same appearance under which the original data were created. This can be done by copying early technical or working systems and software applications (Pandey and Misra, 2014).

\section{Discussion}

Digitization of records and archives can give a lot of benefits to the company. At the same time it will give a better image of an institution when they start to digitize their records and go for paperless. But the digitization also can ruin a record if they cannot properly manage as technology changes rapidly and if they cannot follow the changes, they might be cannot access the record and need a lot of money to retrieve them back. So, should the organization replace all the paper based to the digital form?

It requires a lot of work to turn all the paper-based records to digital form. The organization also needs to prepare for the cost that they need to invest as they need a new expertise or do a trainee program to their staffs. They also need to pay for the maintenance as the technology keeps updating a new format and they need to ensure that they are always following the new format. When an organization starts to digitize all the records, they also need to make a new policy to secure their data as it is easier the information to leak when the systems can be access by everyone.

The policy will help in terms of selection, budgeting, technical requirement, legal aspect, human resource planning, development and maintenance, preservation of digital content and project management where it is very important to help the staffs to provide a better work. From the policy also, they can come out with the risk that they will face and they can make an early preparation to ensure the risks can be overcome. Even though it is not easy to change everything in a digital form, but the information created is keep increasing and it force us to have a better way in managing the records.

\section{Conclusion}

The changes in the information are rapid and it is important for information profession to change with it too. Information was created to share and disseminate the information and the professional needs to ensure that the information can be more easily to share when they decide to digitize the records. They need to be more extra careful on intellectual property but at the same time they have to meet the requirement of their patron. The digitization is very important in this $21^{\text {st }}$ century as the user now prefer to search for information online as it is easier rather than searching for the paperbased records. They need to provide the information as powerful and easy as Google or another search engine. The numbers of patron that use our service shows either the service provided are good enough or not. But the process of digitization might require time and budget but it will give a good image in future. 
INTERNATIONAL JOURNAL OF ACADEMIC RESEARCH IN BUSINESS AND SOCIAL SCIENCES

Vol. 8, No. 9, Sept. 2018, E-ISSN: 2222-6990 (C) 2018 HRMARS

\section{References}

Besser, H. (1999). Implications in digitizing special collections materials: The institution, scholarship, interoperability, legibility. [Online]. Available: http://sunsite.berkeley.ed/imaging/Databases/Conservation/RBM S99/ppframe.html

Cocciolo, A. (2015) "Digitizing oral history: can you hear the difference?", OCLC Systems \& Services: International digital library perspectives, Vol. 31 Issue: 3, pp.125-133, https://doi.org/10.1108/OCLC-03-2014-0019

International Federation of Library Associations and Institutions (March, 2002). Guidelines For Digitization Projects: for collections and holdings in the public domain, particularly those held by libraries and archives.

Retrieved December 21, 2017 from https://www.ifla.org/publications/guidelines-fordigitization-projects-for-collections-and-holdings-in-the-public-domain Ret

International Records Management Trust. (2000). An Introduction to Core Principles for Staff of the World Bank and Its Partners

MS 2473 (2012), Implementation Guidelines for Digitisation of Records. Cyberjaya: Department of Standards Malaysia

Pandey, P. \& Misra, R. (2014) Digitization of Library Materials in Academic Libraries: Issues and Challenges, Journal of Industrial and Intelligent Information, Vol. 2 (2), pp. 136-141.

Riley-Reid, T. D. (2015). The hidden cost of digitization - things to consider, Collection Building, Vol. 34 (3), pp. 89-93, https://doi.org/10.1108/CB-01-2015-0001

Routhier Perry, S. (2014). Digitization and digital preservation: A review of the literature. SLIS Student Research Journal, 4(1). pp. 1-12.

Retrieved from http://scholarworks.sjsu.edu/slissrj/vol4/issl/4

Sarah. S. (2017). The Disadvantages of Records Management. Retrieved from https://bizfluent.com/list-7865748-disadvantages-records-management.html

United Nations Archives and Records Management Section. (2010). Records and Information Management Guidance 